Article

\title{
A Methodology for Assessing the Sustainability of Hydrogen Production from Solid Fuels
}

\section{Nirmal V. Gnanapragasam, Bale V. Reddy and Marc A. Rosen *}

Faculty of Engineering and Applied Science, University of Ontario Institute of Technology, 2000 Simcoe Street North, Oshawa, Ontario, L1H 7K4, Canada; E-Mails: nirmal.vijay@gmail.com (N.V.G.); bale.reddy@uoit.ca (B.V.R.)

* Author to whom correspondence should be addressed; E-Mail: marc.rosen@uoit.ca; Tel.: +1-905-721-8668; Fax: +1-905-721-3370.

Received: 21 February 2010; in revised form: 1 April 2010 / Accepted: 24 May 2010 / Published: 28 May 2010

\begin{abstract}
A methodology for assessing the sustainability of hydrogen production using solid fuels is introduced, in which three sustainability dimensions (ecological, sociological and technological) are considered along with ten indicators for each dimension. Values for each indicator are assigned on a 10-point scale based on a high of 1 and a low of 0 , depending on the characteristic of the criteria associated with each element or process, utilizing data reported in the literature. An illustrative example is presented to compare two solid fuels for hydrogen production: coal and biomass. The results suggest that qualitative sustainability indicators can be reasonably defined based on evaluations of system feasibility, and that adequate flexibility and comprehensiveness is provided through the use of ten indicators for each of the dimensions for every process or element involved in hydrogen production using solid fuels. Also, the assessment index values suggest that biomasses have better sustainability than coals, and that it may be advantageous to use coals in combination with biomass to increase their ecological and social sustainability. The sustainability assessment methodology can be made increasingly quantitative, and is likely extendable to other energy systems, but additional research and development is needed to lead to a more fully developed approach.
\end{abstract}

Keywords: sustainability; solid fuels; coal; biomass; hydrogen energy; hydrogen production 


\section{Introduction}

Concerns regarding such factors as energy, economics and environmental impact have increased interest in sustainable development, particularly the sustainability of energy systems. As a consequence, governments at local, regional, national and intra-national levels have introduced measures and sought agreements to enhance the sustainability of society's energy activities.

Such initiatives are often based on non-rigorous assessments, and thus are sometimes challenged. Structured methodologies for assessing energy sustainability are needed and would make it more straightforward to justify sustainability measures and to obtain support for them.

The importance of energy systems sustainability can be seen by considering climate change [1]. Concerns about the ramifications of climate change have added momentum to the initiatives being considered by governments and industries to switch to non-carbon-based energy sources. Some propose for a hydrogen energy system in which hydrogen and electricity are the primary energy carriers and facilitate the use of non-fossil-based energy resources [2-7]. Many feel that the shift to alternative energy sources would also help to improve national economies by creating new industries and employment opportunities, advance policies to facilitate new investments and business models and create funds for development through large government stimulus packages [7-9]. Hydrogen energy systems could also lead to an increase in the contribution of coal and biomass to local energy markets. When using hydrogen produced from coal or biomass, $\mathrm{CO}_{2}$ emissions can be addressed, making the capture and storage of $\mathrm{CO}_{2}$ more economic [2]. Considering these disparate advantages and disadvantages separately in assessing sustainability is complex, highlighting the need for structured and sound sustainability assessment methodologies.

This article focuses on the need to improve the sustainability of the energy system, and introduces and illustrates a qualitative (and partially quantitative) methodology for evaluating the sustainability of solid fuels in energy systems. The methodology is not fully developed, but rather is suggested as a possible framework which is being developed. In the methodology, indicators are applied to each solid fuel for a variety of factors. The methodology is intended to allow the assessment and comparison of the sustainability of energy systems involving hydrogen production from solid fuels, as well as to facilitate sustainability enhancements. The methodology is illustrated here by comparing two solid fuels for hydrogen production: coal and biomass. The methodology can be made more quantitative with sufficient data.

\section{Background: Methodologies for Assessing Sustainability of Energy Systems}

Measuring sustainability is a major issue as well as a driving force in determining the impact of various indicators on energy systems [10]. Assessment methodologies usually consider at least three dimensions of sustainability: ecological, sociological and technological. Numerous factors within each dimension are often evaluated. An effective sustainability indicator has to meet characteristics reflecting a problem and criteria to be considered [11]. Selection, grouping, judging, weighing and normalizing of these indicators are somewhat subjective and dependent on the domain of a given sustainability analysis $[10,12,13]$.

Various investigations of sustainability have been undertaken, and methodologies and tools for sustainability assessments have been reported [12-15]. An overview of sustainability 
assessment methodologies has been published recently [14], as has an attempt to categorize such methodologies [13]. These methodologies are useful for comparing processes, systems or organizations [12].

Methods for sustainable engineering, for energy and other systems, are becoming more common [16]. On a broader scale, efforts have been made to predict national sustainability [15].

The convergence in sustainability assessments of energetic, economic and environmental factors has been investigated [15], as have the linkages between energy efficiency, sustainability and economic growth [17]. The importance of energy efficiency and thermodynamic analysis in efforts to enhance sustainability has been emphasized [18,19].

The sustainability of energy systems has been investigated [20,21], addressing requirements to understand energy services and policies [22]. In efforts to improve energy sustainability, the importance has been addressed of efficiency and thermodynamics [8,12,23] and sustainability indicators for renewable energy technologies [10]. Furthermore, the use of life cycle assessment as a tool for evaluating the sustainability of energy technologies and fuels has been cited [24], and the use of exergy as a tool for energy sustainability has been examined [18,19,25].

The potential of hydrogen energy systems to contribute to energy sustainability has been assessed [11,26,27], as have strategies for sustainability using hydrogen energy [28].

\section{Sustainability Assessment Methodology and Indicators}

\subsection{Sustainability Assessment Methodology}

A qualitative methodology, which is partially quantitative, is introduced for evaluating the sustainability of energy systems involving hydrogen production from solid fuels. The methodology can be extended to become more quantitative if sufficient data are available. The methodology is not fully developed, but provides a framework which can be refined.

In the method, indicators are applied for a variety of factors. The methodology is intended to allow assessments, comparisons and improvements of the sustainability of energy systems for hydrogen production from solid fuels, and for their components. The assessment methodology considers ecological, sociological and technological dimensions of sustainability, and ten indicators within each dimension. Each sustainability indicator assesses a sustainability criterion. The selection and grouping of the criteria are based on information presented in the literature and reasoned judgment. The criteria are taken to be equally weighted here, but this is simply a first-order simplification. More complex weighting schemes for the different indicators can be introduced that allow sustainability to be better assessed.

The methodology is developed by defining specific indicators whose values are assessed based on relevant reports in the literature. The methodology may be extendable to sustainability assessments of various other energy conversion systems, provided appropriate variables and indicators are specified and assigned values. 


\subsection{Sustainability Indicators}

The indicators for each of the three dimensions of sustainability are chosen so that they are mostly independent of the indicators in other dimensions, but related to them in the broader sense of the hydrogen product.

The index values for each indicator are related to other indicators depending on their definitions, and governed by energy, economy and environment considerations. The value of indices is chosen based on relevant information in the literature. The index value ranges from 0 to 1 divided into 10 steps. Although index values are chosen based on an examination of pertinent data and information, the assignment is somewhat subjective. The expectations for a maximum value of 1 is kept very high in this work, so only very few elements within the system are capable of receiving a value of 1 for some of the indicators.

The term "element" in this work means a natural resource such as solid fuels, or any other unitary item involved in the system being assessed. The term "process" means an activity which involves more than one item in making a desired output.

The three dimensions of sustainability (ecological, sociological, technological) in the proposed methodology are discussed in the next three sections, along with the indicators applied within each dimension.

\subsection{Linking of Sustainability Dimensions}

Figure 1 shows the linking of the three dimensions of sustainability (ecology, sociology and technology) with three principles of sustainability: economy, environment and effort by people to prolong standards of life into the future (depicted as light grey area in Figure 1). Each indicator within a given dimension (depicted as triangles in Figure 1) in the current work is valued based on the impact of the indicator on the three principles of sustainability. The indicators in each of the three dimensions are linked based on these three principles. Technology indicators are linked to ecological indicators through the environment, implying that technological improvements should result in responsible use of ecological resources, with as little damage to the environment as possible. Technology indicators are linked to sociological indicators through the economy, implying that society benefits through economic developments induced by technological advancements, especially in the current work which focuses on solid fuel sources delivering energy services to society when and where they are in demand. Ecology and sociology are linked through human effort in improving social living standards and governance while caring for the ecology that supports it now and in the future.

The size of the grey area for "human effort" in Figure 1 is smaller compared to "economy" or environment," denoting the greater influence of the latter two on sustainability compared to human effort. In order to improve sustainability in the future, human effort needs to increase, as the influence from environment will likely grow, decreasing the influence of the economy. In the future, therefore, greater effort by people (requiring more monetary infrastructure) to tackle decreases in resources and environmental degradation may reduce the influence of the economy. For example, more eco-friendly policies and mandates by governments exist across the world now than ever before [29], highlighting a shift toward the environment instead of the economy. Hence, the values assigned to some of the 
sustainability indicators in this work may change in the future, causing a shift away from utilizing some solid fuels.

Figure 1. Linkages among sustainability dimensions.

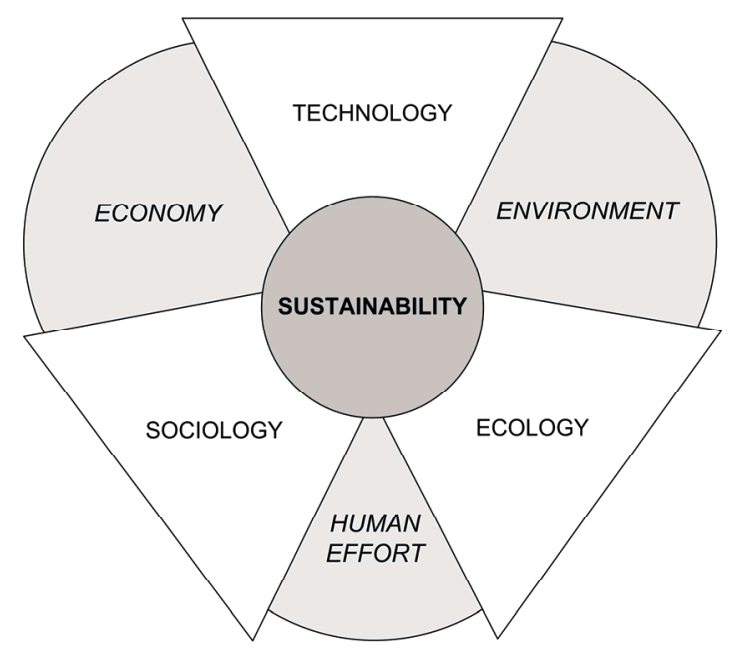

\section{Ecological Indicators}

In this work, ecological indicators [10] help in assessing ecosystems and the impact on them of human activity, which can be local, regional or national. The indicator values specify the ecological sustainability of a particular element or process within a system. These indicators highlight the impact of each element or process on changes to the environment.

1. Availability: Sustainable availability of the element within the relevant energy market $[1-7,29,30]$. The highest value of 1 is assigned for such elements or processes that are available in the local market at competitive price and the lowest value of 0 is assigned for lack of availability. For example, coals are abundant in Canada, the USA, Poland and other countries [4], providing ample supplies for longer periods of time at low costs. The sustainability index is higher for any commercially available process.

2. Adaptability: Requiring fewer processes to acquire and process the element, minimizing waste generation [1,3,31-34]. A value of 1 is assigned if an element or process is highly adaptable and 0 for the least adaptable item in a system. For example, ecological sustainability is higher for solids handling processes than for gasification process, since the former is already an established industry serving the coal power plants $[1,35]$.

3. Environmental capacity: Length of time the global ecosystem can supply and support the element or process, without creating significant imbalances within the global ecosystem [4,6,35-39]. A value of 1 is assigned if an element or process can be sustained for a long time even with an increase in demand for it in the market place. A value of 0 is assigned if little of the resource is available in the local market and it impacts the ecosystem significantly. For example, a process which is capable of recycling is assigned a higher index than a process that has less probability for reusing some of its wastes or by-products. 
4. Timeline: Newness or maturity of the element or process, weighted by its evolution $[5,29,40,41]$ within the market place. A value of 1 denotes that a well established process that has greatly evolved since its creation, while a value of 0 denotes that the element is "fossilized" and has little chance for further improvement. For example, commercial gasification is a mature technology with less opportunity for major improvements or evolution.

5. Material rate: Rate at which the element/process or products for and from the element/process can be procured [4,30,37,38,42-44], accounting for the effectiveness of raw material and product distribution networks. A value of 1 is assigned to the best network and 0 for the worst. For example, coals have higher material rate sustainability index (up to 0.9) than biomasses (up to 0.5), due to the well established network of mining and distribution.

6. Energy rate: Rate at which energy can be supplied by the element or process $[4,30,45,46]$. A value of 1 denotes a high energy supply rate and 0 a low energy supply rate. This indicator measures the ecological energy density for an element or process, the amount of energy available per unit volume of space per time period. For example, combustion processes have a very high energy rate compared to other process due to higher rate of chemical reaction. Coals have a high energy rate in that they can deliver more energy per unit mass and time than biomasses. Although this indicator value implies that combustion is advantageous based on this individual index - in terms of delivering a high energy rate, the value does not imply that combustion is more sustainable overall, as the other indicators need to be evaluated and combined to make that determination.

7. Pollution rate: Rate of pollution or emissions associated with the element or process [1-4,24,37,47-50]. A value of 1 is assigned if there is a low pollution rate and a value of 0 if there is high pollution rate. For coal combustion, for example, technologies for removal of sulphur compounds $\left(\mathrm{SO}_{2}, \mathrm{H}_{2} \mathrm{~S}, \mathrm{COS}\right)$ are well evolved (suggesting that they help in reducing the rate of pollution), so they merit a higher index value than $\mathrm{CO}_{2}$ separation and storage, which is not yet commercialized.

8. Location: Nearness of the element/process from the point of use [13,33,36,51]. A value of 1 is assigned if the source is near to the point of use and 0 if it is far. The system can be placed near to the main solid fuel source. If the other elements and processes are to be moved to the system location, its operating and maintenance costs increase. Thus for coals and other mine-based solid fuels, low values are assigned here.

9. Ecological balance: Element or process that creates an imbalance in the local ecosystem. This measure also indicates the level of recyclability or reuse of the element or process $[46,52,53]$. A value of 1 is assigned if most of the element or process is recyclable or reusable and a value of 0 is assigned if recycling is not achievable. For example, coal scores a 0 in this regard whereas renewable biomass scores a higher value, which also depends on availability.

10. Endurance: Element work load or demand factor and a process requiring equipment maintenance [1-4,46,52,53]. A value of 1 is assigned if the element or process has a high load and demand with lower maintenance and a value of 0 is assigned when there is high maintenance irrespective of high or low load. For elements such as fuels that require high equipment maintenance, a lower index value is assigned for this sustainability indicator. 


\section{Sociological Indicators}

Sociological indicators help in assessing impacts on the social system and help guide system changes [14]. The social system represents the communities that benefit directly and indirectly from the operation and products of the system. Ten sociological indicators specify the sustainability of an element or process within the social system and help avoid undesirable effects. Ten sociological indicators, which are assigned values ranging from a high of 1 to a low of 0 , are considered:

1. Economics: Economic and financial benefits from the element or process $[5,12,13,23,29,31,33,45,54-57]$. A value of 1 is assigned if maximum net economic benefit derived from the final product (hydrogen) and a value of 0 is assigned when there is a net economic loss from transforming solid fuels to hydrogen. For example, commercial gasification provides more overall economic benefit due to its higher volume of hydrogen production in less time, than solar thermal gasification.

2. Policy: Government policies and implementation trends $[1,5,7,31,32,35,36,38,39]$ that affect the availability of an element or development of a process. A value of 1 is assigned if the policies and implementation strategies support the sustainability of an element or process and a value of 0 is assigned if they act as hindrances. Values are chosen based on advancements in technology in dealing with energy, environment and economics of processes and ecological sustainability of solid fuels for hydrogen production. For example, a government initiative to increase funding for biomass research helps in improving the sustainability of such hydrogen production processes.

3. Human resources: Level of direct human work input in procuring, manufacturing, installing and operating an element or process [5,44,46,50,52,53]. A value of 1 is assigned if more human work is involved, owing to the job creation and resulting economic benefit for society. A value of 0 is assigned if no direct human work is involved with an element or process. For example, solids handling and waste disposal involve more human labour than gasification or combustion (except during installation and maintenance).

4. Public opinion: Public opinion regarding the nature and operation/behaviour of an element or process $[15,18,22,44]$. A value of 1 is assigned if the majority of the population have a positive opinion relating to an element or process and a value of 0 is assigned if there is a negative opinion. For example, $\mathrm{CO}_{2}$ emissions from fossil fuels have been highlighted by the media and government bodies as the main cause of climate change [6], so any element or process which does not emit $\mathrm{CO}_{2}$ or reduces its concentration in the atmosphere is assigned a higher value since it generates positive public opinion. Public opinion often transforms into government policies, which can lead to support for measures that curb harmful emissions.

5. Environmental obligation: Social expectations regarding the environmental obligation of an element or a process and its by-products to be benign to the environment in which society functions [6,29,33,37,47]. A value of 1 is assigned if the operation and by-products of the element/process are environmentally benign and a value of 0 is assigned if a process or element is necessary to the system's operation but harmful to the environment. This indicator encourages the elimination of process that requires additional measures to protect the environment. For example, converting $\mathrm{CO}_{2}$ to biodiesel using sunlight or nutrients from the 
biogas by-product associated with using algae is environmentally benign in that it not only consumes $\mathrm{CO}_{2}$ but also provides an alternate fuel. So, converting $\mathrm{CO}_{2}$ to algae is assigned a higher social index value than other $\mathrm{CO}_{2}$ sequestration methods like underground $\mathrm{CO}_{2}$ storage that require further processes.

6. Living standards: Impact of an element or process on human living standards, focusing on basic requirements such as food, clothing and shelter [29,58]. A value of 1 is assigned if an element or process within the system improves human living standards indirectly. A value of 0 is assigned if an element or process does not improve basic living standards. For example, coals are assigned a higher index than biomass due to their higher energy densities, which helps in producing more hydrogen; this in turn can provide additional goods and services compared to biomass, thereby improving basic human living standards. Even with high energy and economic penalties for pollution control measures, coal can still produce more hydrogen than biomass [29].

7. Human convenience: Impact of an element or process on human convenience (higher living standards and comforts beyond the necessity for basic living standards) [29,58]. A value of 1 is assigned if an element or process within the system helps in providing human comforts and a value of 0 is assigned if an element or process does not provide human comfort, through additional hydrogen production. The index values for solid fuels are similar to those for the previous indicator (\#6). But for some processes, the index value may be lower, e.g., if more fuel is used due to increased secondary and environmental protection in producing hydrogen.

8. Future development: Possibilities for future economic and social growth based on the nature of an element or process [1-6,45,54-57]. A value of 1 is assigned if using the element or process increases the possibility for societal development. A value of 0 is assigned if using the element or process within the proposed system does not provide such opportunities, even in the local community.

9. Per capita demand: Impact of population/customer demand on producing hydrogen with the element or process, affecting its sustainably $[6,29,58]$. A value of 1 is assigned if fewer industries use the element or process, thereby increasing market availability and, possibly, price competitiveness. A value of 0 is assigned when the element or process is used by many industries, which hinders availability and sustainability. For example, coals are mostly used for power generation and in steel industries and, based on its per capita availability, are assigned high values. But biomass per capita availability is small and is mostly used in co-combustion processes or as manure, reducing the per capita demand sustainability index.

10. Lobbying: External influences on the impact of an element or process, through political and economic lobbies that can affect government sustainability policies $[29,32,37,38,41,43,59]$. A value of 1 is assigned if the process or element has effective lobbying and a value of 0 is assigned if no lobbying is attempted. For example, the coal industry is established and is engaged in many markets in political lobbying to maintain its use and to promote supportive government policies [59]. In recent years, green energy programs have received extensive lobbying due to their potential long-term contributions in mitigating climate change, processes associated with green energy policies are assigned higher index values. 


\section{Technological Indicators}

Technological indicators help in assessing the knowledge, design, performance and production aspects of an element or process for hydrogen production from solid fuels, from an engineering perspective. The indicators assess the technical capabilities of each element in a system, and their values specify the sustainability of the system and its components, considering energy affordability, environmental limitations, commercialization possibilities and potential progress with respect to hydrogen production.

1. Net energy consumption: Energy requirement of the element to transport it to the point of use and utilize it in the operation of processes [12,29,34,40,46,54,56,58,60-63]. A value of 1 is assigned if the element or process requires little energy and a value of 0 if it requires much energy. For example, processes that generate energy (e.g., electricity generation) have higher index values than those that consume energy.

2. Exergy: Relative exergy of the element or process with respect to the system and the environment [29,30]. A value of 1 is assigned for an element with high exergy or for a process that has lower exergy destruction and a value of 0 is assigned for an element with low exergy or for a process with high exergy destruction. For example, combustion has higher exergy destruction than gasification, so combustion processes are assigned lower index values for exergy.

3. Efficiency: Efficiency (ratio of desired output to input, considering both energy and exergy) of element or process and related technology in hydrogen production [46,52,53]. A value of 1 is assigned for processes having high efficiencies (above 0.9 ) and a value of 0 is assigned for processes with very low efficiencies (below 0.1). For example, commercial electrolysers have energy efficiencies ranging typically from 0.5 to 0.7 [29].

4. Design: Impact of design of a process or an element on sustainable operation of the system [7,28,31-33,63]. A value of 1 is assigned for the best design, taken to be a design that, among other factors, improves the overall performance of the system and minimizes waste generation. A value of 0 is assigned for the worst design. For example, a low index value (0.3) is assigned for ultra superheated steam (USS) gasification since it is still in the research phase but has significant future potential.

5. Research: Impact of research on future developments of a process or an element that affect the ability of a system to produce hydrogen sustainably [7,28,29,31-33,35,63]. A value of 1 is assigned for an element or process with high probability for successful research and a value of 0 is assigned when there is a low probability for research advances. For example, the amount of research for plasma gasification and $\mathrm{CO}_{2}$-to-algae conversion processes, due to technology prospects and incentives, is sufficient to merit higher index values.

6. Demonstration: Capacity for demonstration of the impact of an element or a process in contributing to hydrogen production in the system [3,29,54,64-68]. A value of 1 is assigned if the process or element has already been demonstrated, while a value of 0 is assigned if there is a need for demonstration to establish the capability of the technology. For example, commercial gasification and solids handling processes have high index values, since they are 
commercially established processes in terms of operation and performance, compared to the ones undergoing research like $\mathrm{CO}_{2}$-to-algae conversion or USS gasification.

7. Commercialization: Potential for process or element technology to become commercially viable, enabling sustainable operation within a system [1-5,23,29,34,35,40,69]. A value of 1 is assigned for processes or elements with high potential for commercialization and a value of 0 is assigned for processes with little commercialization potential. For example, USS gasification is assigned a low value (0.4) since it has limited potential for commercial development due to size constraints (i.e., large-scale operation has low efficiencies which increase operating costs). Conventional gasification is assigned a high value (0.9) since it operates commercially on a large-scale and is the fastest growing segment within the coal industry due to its ability to produce synthetic gases [34].

8. Impact: Impact of actual process or element on sustainability of the system for producing hydrogen $[12,23,29,35,45,46,62,69,70-72]$. A value of 1 is assigned to processes or elements that have a high impact on the system's performance and a value of 0 is assigned to those that have low impact. For example, within the commercial gasification process, the air separation unit (ASU) is assigned a higher value than the ash handling system because it is crucial to a high-efficiency solid-to-gas conversion as well as effective downstream $\mathrm{CO}_{2}$ capture. The ASU therefore has a significant impact on improving the overall efficiency of the system for producing hydrogen, whereas the ash handling system, although essential, does not impact the system efficiency as much as the ASU.

9. Evolution: Capacity for process technology to improve, adapt and grow in the market place $[4,5,7,29,31,35,38,50,59]$. A value of 1 is assigned to processes that have high opportunities for evolving to increase efficiency and decrease operating and maintenance costs, while a value of 0 is assigned to processes with little opportunity for such development. For example, commercial gasification has little chance for evolution, whereas supercritical water gasification is expected to evolve into an efficient process for large-scale hydrogen production that is useful for effective disposal of sewage water [71].

10. Environmental limitations: Limitations of process technology arising from harmful impact on the environment while operating within the system [6,32,33,36,47,66,73,74]. A value of 1 is assigned to processes with few limitations in operation due to environmental damage, while a value of 0 is assigned to the processes with high limitations in operation due to their environment impacts. For example, devices that contribute to pollution control within the system, such as the ash collector, syngas cleaner and membrane separator, have high index values since they are subject to few environmental limitations and they contribute to environmental preservation.

\section{Advantages and Disadvantages of the Methodology}

The main objective of this article is to develop an index to assess and compare systems. This objective has been met in a preliminary manner in this article, but as noted earlier further effort to refine the methodology is ongoing. At present, the indicators are defined using both objective and subjective information, and a normalized range varying between zero and unity is applied. The results 
are therefore generally comparable, but some inconsistencies can occur in comparative assessments for some factors. Efforts to reduce the subjective aspects of the methodology are ongoing by the authors, although it is anticipated that it will not be possible to remove all subjectivity as some subjectivity is inevitable.

Both qualitative and quantitative evaluation methods are incorporated within the methodology. The quantitative methods are used for factors that are more clearly measurable (e.g., efficiency, greenhouse gas emissions, costs), but these quantitative methods do not encompass all relevant sustainability factors. The qualitative evaluations allow many factors that can not be accounted for straightforwardly or readily with the quantitative evaluations to be addressed, thereby rendering the methodology more comprehensive. Nevertheless, the qualitative factors can make the ranking method somewhat subjective, due to the difficulty in measuring them. The number of qualitative indices in the overall ranking system is thus kept as low as reasonably possible so as to avoid having the subjectivity of the result become excessive.

One approach to assessing the degree of subjectivity introduced via qualitative indices is to perform a sensitivity analysis over the range of possible values for most of the qualitative or subjective indicators, and from that analysis identify ranges of "acceptable" values. Such an investigation is highly complex, and is the subject of ongoing research by the authors. The outcomes of that research may allow the subjectivity of the methodology introduced in this article to be reduced somewhat, but there will nonetheless remain a substantial degree of subjectivity due to the non-measurable nature of many factors.

Much effort was dedicated by the authors to developing for each of the three main sustainability dimensions (ecological, sociological, technological) criteria that are comprehensive and consistent, yet limited enough in number to be tractable. The authors made many trade-offs before deciding on ten factors for each sustainability dimension. An equal number of sustainability criteria are considered in each dimension to ensure that each receives prominence. The criteria are defined for the overall system as well as its processes or components or elements in as consistent manner as possible. Nonetheless, it is recognized that aspects of the measures may be inconsistent, although the impact of such inconsistencies on the overall results appear to be small. Nonetheless efforts are ongoing to reduce any inconsistencies.

One weakness in the present methodology is the fact that some of the criteria are related. For instance, efficiency and design overlap to some degree, while research, commercialization and evolution have some commonalities. Although it is difficult, if not impossible, to make all indicators within one sustainability dimension completely independent, we feel that the essential aspects of most of the criteria are independent, thereby allowing valid assessments to be made. However, modifications to the criteria to increase the degree of independence may be possible. Sustainability indicators should nonetheless always reflect the reality that the three sustainability dimensions are interconnected, forming a web of information from which qualitative and quantitative assessments can be made, for energy sources (as in the current work) or broader energy systems (as planned for future works). 


\section{Illustrative Example: Hydrogen Production from Coal and Biomass}

The methodology introduced here is illustrated to assess and compare in a Canadian context two solid fuels for hydrogen production: coal and biomass. Hydrogen is considered to be the most advantageous alternative fuel for mitigating direct $\mathrm{CO}_{2}$ emissions to the atmosphere [7] from carbon-based solid fuels, while still providing the goods and services required by society. In most countries, hydrogen is not presently used extensively as a fuel, although it is often utilized as a feedstock for chemical and petrochemical processes in industry.

The production of hydrogen from solid fuels like coal and biomass are considered by some to be advantageous. Hydrogen production from solid fuels involves the supply, processing and drying of the fuels, primary energy conversion processes (e.g., gasification), and secondary processes like gas and waste treatment. In this example, only the fuels, rather than the entire process, are assessed.

For coal types are considered here: anthracite, bituminous coal, sub-bituminous coal, and lignite/brown coal. Also, three types of biomass are included in the assessment: forest biomass, farm biomass and energy crops.

The sustainability indices are tabulated for the indicators in the three sustainability dimensions: ecological (Table 1), sociological (Table 2) and technological (Table 3). The index values for each solid fuel are averaged across the 10 indicators in each sustainability dimension. The averages are evaluated as simple means. Averaging sustainability indices may not provide the exact impact on sustainability of solid fuels, but it does provide a broad understanding of their sustainability. This approach is not based on a rigorous rationale, but rather is a simplified first-order assessment. To facilitate comparisons and illustrate the results, the average sustainability indices in each of the three dimensions are plotted on a three-axis graph in Figure 2 for coals and Figure 3 for biomass.

Table 1. Sustainability indices for hydrogen production from solid fuels for ecological indicators.

\begin{tabular}{|c|c|c|c|c|c|c|c|c|c|c|c|}
\hline & \multicolumn{11}{|c|}{ ECOLOGICAL INDICATORS } \\
\hline & 1 & 2 & 3 & 4 & 5 & 6 & 7 & 8 & 9 & 10 & Total \\
\hline SOLID FUELS & 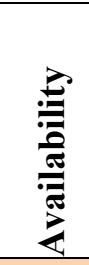 & 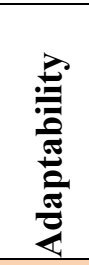 & 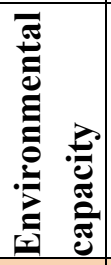 & $\stackrel{\mathscr{\Xi}}{. \Xi}$ & 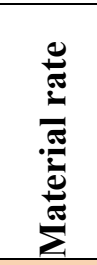 & 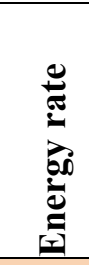 & 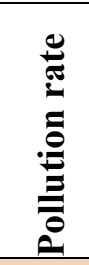 & 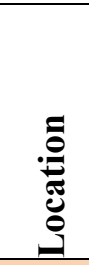 & 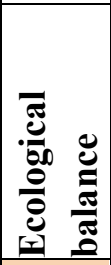 & 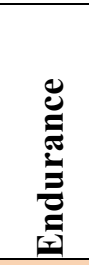 & 空 \\
\hline COALS & 0.80 & 0.15 & 0.20 & 0.13 & 0.78 & 0.63 & 0.10 & 0.35 & 0.00 & 0.75 & 0.39 \\
\hline Anthracite coal & 0.5 & 0.1 & 0.2 & 0.1 & 0.7 & 0.8 & 0.1 & 0.2 & 0 & 0.5 & 0.32 \\
\hline Bituminous coal & 0.8 & 0.1 & 0.2 & 0.1 & 0.7 & 0.7 & 0.1 & 0.3 & 0 & 0.8 & 0.38 \\
\hline Sub-bituminous coal & 1 & 0.2 & 0.2 & 0.1 & 0.9 & 0.5 & 0.1 & 0.5 & 0 & 0.9 & 0.44 \\
\hline Lignite or brown coal & 0.9 & 0.2 & 0.2 & 0.2 & 0.8 & 0.5 & 0.1 & 0.4 & 0 & 0.8 & 0.41 \\
\hline BIOMASSES & 0.43 & 0.47 & 0.50 & 0.70 & 0.50 & 0.43 & 0.53 & 0.47 & 0.20 & 0.40 & 0.46 \\
\hline Forest biomass & 0.5 & 0.5 & 0.5 & 0.6 & 0.5 & 0.4 & 0.5 & 0.4 & 0.1 & 0.3 & 0.43 \\
\hline Farm biomass & 0.6 & 0.6 & 0.6 & 0.7 & 0.5 & 0.5 & 0.5 & 0.4 & 0.2 & 0.2 & 0.48 \\
\hline Energy crops & 0.2 & 0.3 & 0.4 & 0.8 & 0.5 & 0.4 & 0.6 & 0.6 & 0.3 & 0.7 & 0.48 \\
\hline
\end{tabular}


Table 2. Sustainability indices for hydrogen production from solid fuels for sociological indicators.

\begin{tabular}{|c|c|c|c|c|c|c|c|c|c|c|c|}
\hline & \multicolumn{11}{|c|}{ SOCIOLOGICAL INDICATORS } \\
\hline & 1 & 2 & 3 & 4 & 5 & 6 & 7 & 8 & 9 & 10 & Total \\
\hline SOLID FUELS & 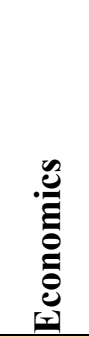 & $\begin{array}{l}\stackrel{3}{0} \\
\stackrel{0}{0}\end{array}$ & 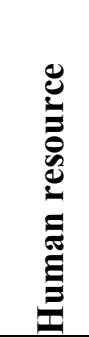 & 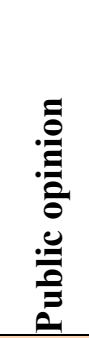 & 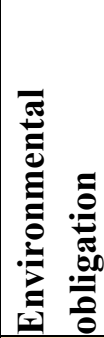 & 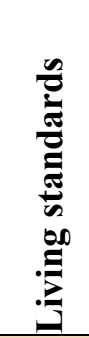 & 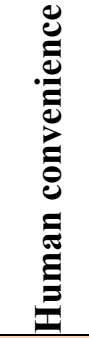 & 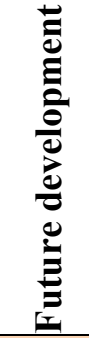 & 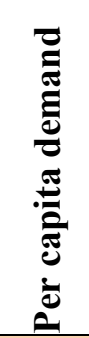 & 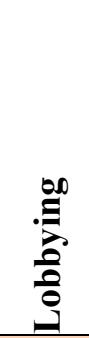 & 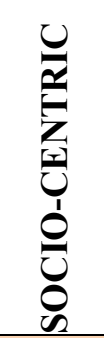 \\
\hline COALS & 0.60 & 0.50 & 0.70 & 0.10 & 0.10 & 0.70 & 0.70 & $\mathbf{0 . 5 0}$ & 0.80 & 0.80 & 0.55 \\
\hline Anthracite coal & 0.6 & 0.5 & 0.7 & 0.1 & 0.1 & 0.7 & 0.7 & 0.5 & 0.8 & 0.8 & 0.55 \\
\hline Bituminous coal & 0.6 & 0.5 & 0.7 & 0.1 & 0.1 & 0.7 & 0.7 & 0.5 & 0.8 & 0.8 & 0.55 \\
\hline Sub-bituminous coal & 0.6 & 0.5 & 0.7 & 0.1 & 0.1 & 0.7 & 0.7 & 0.5 & 0.8 & 0.8 & 0.55 \\
\hline Lignite or brown coal & 0.6 & 0.5 & 0.7 & 0.1 & 0.1 & 0.7 & 0.7 & 0.5 & 0.8 & 0.8 & 0.55 \\
\hline BIOMASSES & 0.53 & 0.73 & 0.63 & $\mathbf{0 . 7 0}$ & 0.70 & $\mathbf{0 . 3 3}$ & 0.40 & $\mathbf{0 . 7 7}$ & 0.33 & 0.63 & 0.58 \\
\hline Forest biomass & 0.7 & 0.8 & 0.6 & 0.8 & 0.7 & 0.3 & 0.3 & 0.8 & 0.4 & 0.6 & 0.60 \\
\hline Farm biomass & 0.8 & 0.8 & 0.6 & 0.8 & 0.7 & 0.4 & 0.4 & 0.8 & 0.4 & 0.6 & 0.63 \\
\hline Energy crops & 0.1 & 0.6 & 0.7 & 0.5 & 0.7 & 0.3 & 0.5 & 0.7 & 0.2 & 0.7 & 0.50 \\
\hline
\end{tabular}

Table 3. Sustainability indices for hydrogen production from solid fuels for technological indicators.

\begin{tabular}{|c|c|c|c|c|c|c|c|c|c|c|c|}
\hline & \multicolumn{11}{|c|}{ TECHNOLOGICAL INDICATORS } \\
\hline & 1 & 2 & 3 & 4 & 5 & 6 & 7 & 8 & 9 & 10 & Total \\
\hline \begin{tabular}{|l} 
SOLID FUELS \\
\end{tabular} & 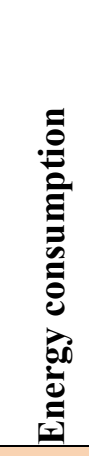 & 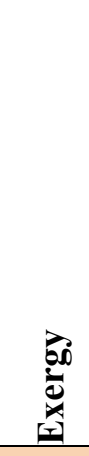 & 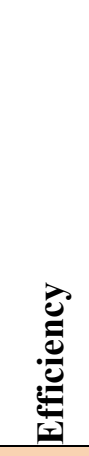 & 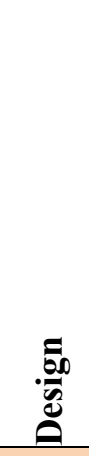 & 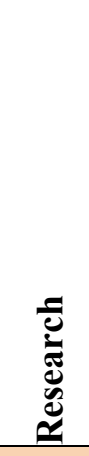 & 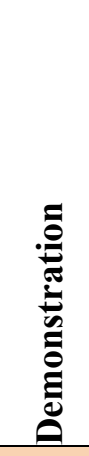 & 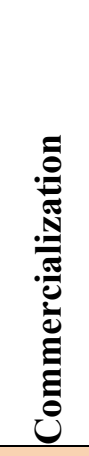 & $\begin{array}{l}\stackrel{\bar{U}}{\tilde{\Xi}} \\
\stackrel{\Xi}{\Xi}\end{array}$ & 总 & 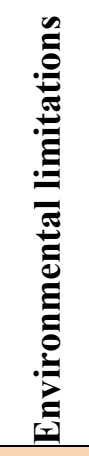 & 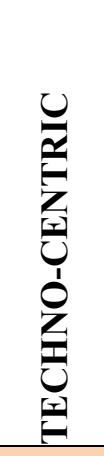 \\
\hline COALS & 0.55 & 0.75 & 0.60 & 0.60 & 0.60 & 0.60 & 0.60 & 0.70 & 0.70 & $\mathbf{0 . 5 3}$ & 0.62 \\
\hline Anthracite coal & 0.5 & 0.9 & 0.6 & 0.6 & 0.6 & 0.6 & 0.6 & 0.7 & 0.7 & 0.4 & 0.62 \\
\hline Bituminous coal & 0.6 & 0.8 & 0.6 & 0.6 & 0.6 & 0.6 & 0.6 & 0.7 & 0.7 & 0.5 & 0.63 \\
\hline Sub-bituminous coal & 0.6 & 0.7 & 0.6 & 0.6 & 0.6 & 0.6 & 0.6 & 0.7 & 0.7 & 0.6 & 0.63 \\
\hline Lignite or brown coal & 0.5 & 0.6 & 0.6 & 0.6 & 0.6 & 0.6 & 0.6 & 0.7 & 0.7 & 0.6 & 0.61 \\
\hline BIOMASSES & 0.60 & 0.53 & 0.57 & $\mathbf{0 . 5 7}$ & 0.73 & 0.60 & 0.77 & 0.60 & 0.70 & 0.80 & 0.65 \\
\hline Forest biomass & 0.6 & 0.5 & 0.5 & 0.5 & 0.7 & 0.5 & 0.7 & 0.6 & 0.5 & 0.7 & 0.58 \\
\hline Farm biomass & 0.7 & 0.5 & 0.5 & 0.5 & 0.7 & 0.6 & 0.8 & 0.7 & 0.8 & 0.8 & 0.66 \\
\hline Energy crops & 0.5 & 0.6 & 0.7 & 0.7 & 0.8 & 0.7 & 0.8 & 0.5 & 0.8 & 0.9 & 0.70 \\
\hline
\end{tabular}


Figure 2. Sustainability indices (\%) for coals used for hydrogen production.

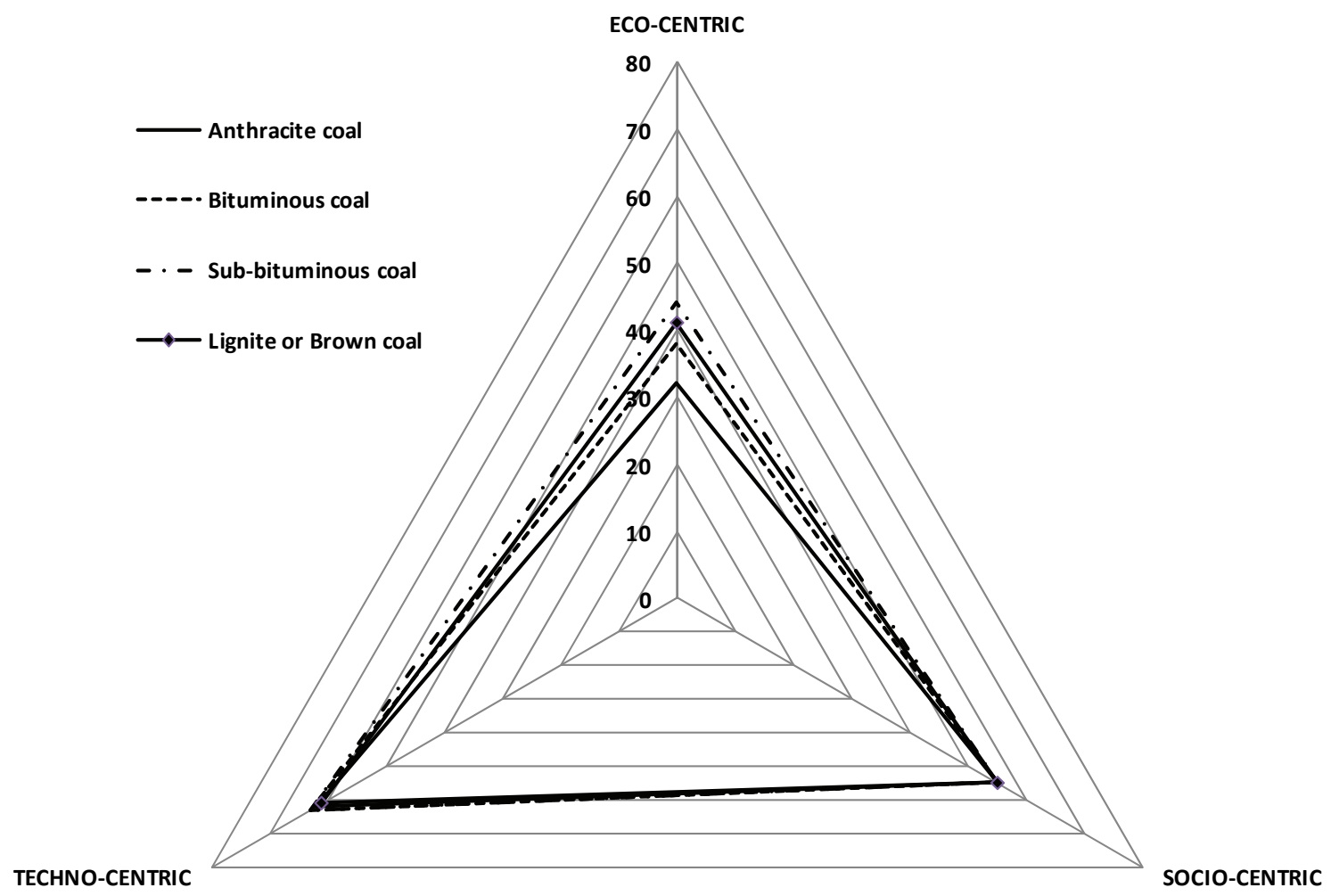

Figure 3. Sustainability indices (\%) for biomass types for hydrogen production.

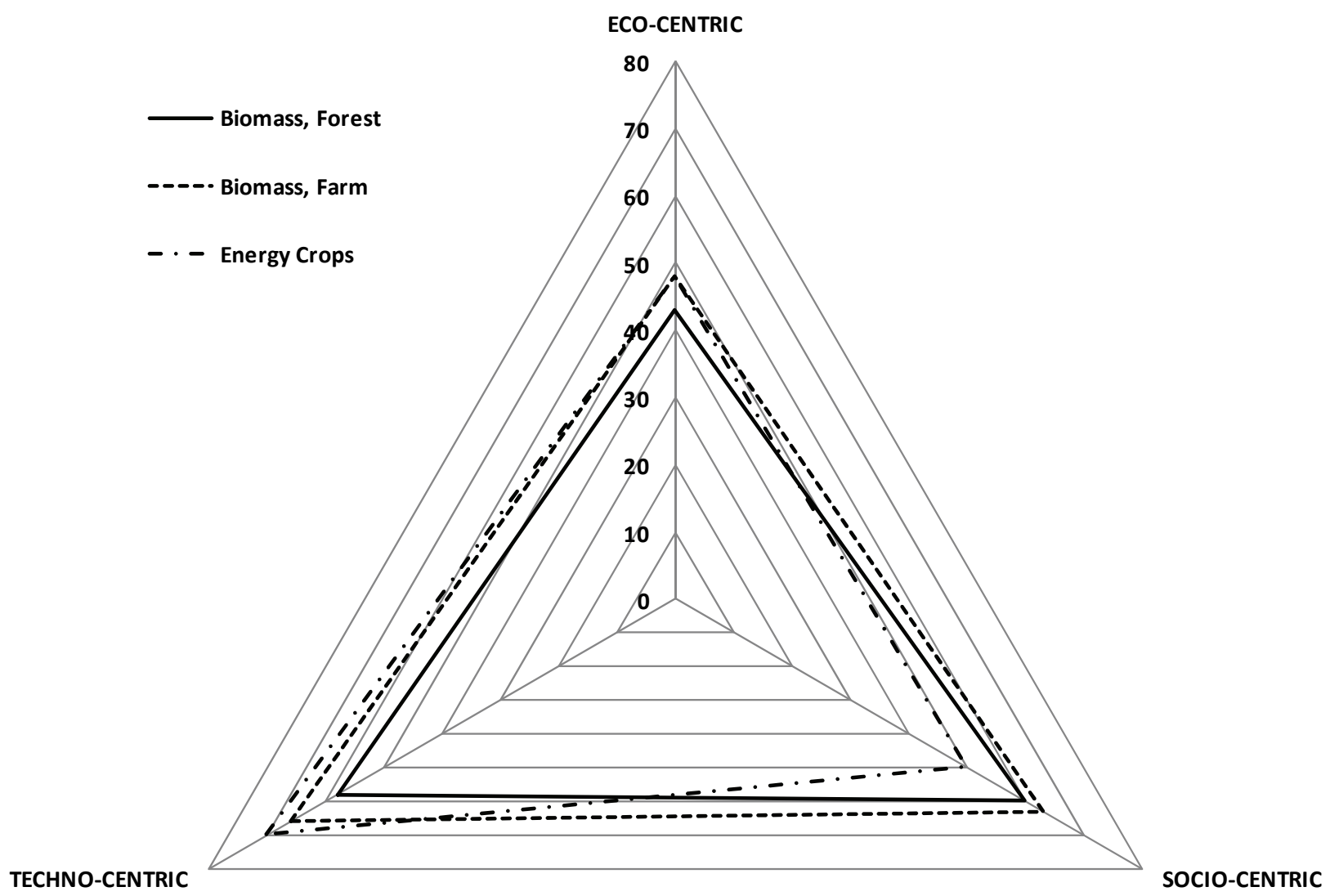




\subsection{Sustainability of Coals}

Since coals are already an established fuel for the electricity market, its sustainability is above average. Of the total coal supply in Canada, $77 \%$ is used for electricity generation [4] in over 60 coal combustion power plants [1] totaling over $17 \mathrm{GW}$ of electricity generation capacity. Of this capacity, $44 \%$ is located in from Ontario, 34\% in Alberta, 10\% in Saskatchewan, 7\% in Nova Scotia, 3\% in New Brunswick, and 1\% in Manitoba, based on data for the year 2004. About $8 \%$ of the coal supply is used by industries for coking and gas manufacture. Despite large Canadian coal reserves [37], potential applications for coal are limited to electricity generation and some industrial use [44], because natural gas and crude oil resources have higher market values.

It is evident in Figure 2 that all coals have less than average values for ecological sustainability, with anthracite at about $31 \%$. This is largely due to the lower environmental capacity exhibited by coals and potential ecological imbalances from their use. Ecological sustainability takes into account the range of dimensions discussed in Section 4 (e.g., environmental capacity, pollution rate, ecological balance). All coals have the same values for technological and sociological dimensions. Some specific observations for the different sustainability dimensions follow:

- Ecological: Coals score high (about 70\%) in availability, material rate and endurance and low (less than 20\%) in adaptability, pollution rate and ecological balance.

- Sociological: Coals are assigned high scores for per capita demand and lobbying and low scores for public opinion and environmental obligation.

- Technological: Coals score high on exergy and technology impact, and are assigned for all indicators reasonably high index values (above 50\%). This result demonstrates the characteristics of industries associated with coals: power generation, steel and petrochemical.

\subsection{Sustainability of Biomass}

Biomass is used in co-firing and co-gasification applications in Canada. Few units converting biomass to electricity are in operation in Canada, with less than $50 \mathrm{MW}$ of electrical generating capacity per unit $[45,54]$. These plants produce little (below 5\%) of the electricity used in the province of Ontario, partly due to a lack of higher conversion potential with biomass fuel for most applied energy technologies.

Figure 3 shows the averaged sustainability triangle for the biomass types considered. Biomass from farms is assigned a higher index value (10\% higher) than biomass from forests, due to a higher average score in the technological dimension. This result is mainly due to the nature of the feedstock, which is drier and bulkier than forest biomass, thereby enabling higher values for evolution, commercial and net energy consumption indicators. The overall sustainability score of biomasses can be expected to increase once a market and demand are established. Some specific observations for the different sustainability dimensions follow: 
- Ecological: Farm biomass and energy crops have the same average index values.

- Sociological: Biomasses have high values (over 70\%) for economics, public opinion and lobbying.

- Technological: Most biomasses are similar and are assigned the high values. This is due to the above-average values scored by biomasses and energy crops. Energy crops are assigned the highest value $(90 \%)$ for environmental limitations in the use of technology relating to its processing.

\section{Conclusions}

A possible methodology has been introduced for assessing the sustainability of hydrogen production using solid fuels. In the sustainability assessment, three dimensions (ecological, sociological and technological) and 10 indicators for each dimension are considered. Values for each of the indicators are evaluated using a 10-point scale based on a high of 1 and a low of 0 , depending on the characteristic of the criteria associated with each element or process, utilizing data reported in the literature. Several conclusions can be drawn from the current work. First, qualitative sustainability indicators can be reasonably defined based on evaluations of system feasibility, and adequate flexibility and comprehensiveness is provided through the use of 10 indicators for each of three dimensions (ecology, sociology, technology) for every process or element involved in hydrogen production using solid fuels. Second, the assessment values of indices for solid fuels suggest that biomasses have better sustainability than coals, and that it may be advantageous to use coals in combination with biomass to increase their ecological and social sustainability. The methodology for assessing the sustainability can be made increasingly quantitative, and is likely extendable to other energy systems. Since the methodology is proposed as a possible framework, additional research and development is needed to attain a more fully developed approach, and this is the subject of ongoing work by the authors. A discussion of the advantages and disadvantages of the methodology is provided to identify and guide important further developments. An application of this methodology to a large-scale hydrogen production system to assess its sustainability is underway, and will assist in the further development of the methodology.

\section{Acknowledgements}

The authors kindly acknowledge the financial support provided by the Natural Sciences and Engineering Research Council of Canada.

\section{References and Notes}

1. Canada's Clean Coal Technology Roadmap; CANMET Energy Technology Center, Natural Resources Canada: Ottawa, ON, Canada, 2005.

2. Clean Coal Technologies in Japan: Technological Innovation in the Coal Industry; Technical Report; New Energy and Industrial Technology Development Organization (NEDO): Kanagawa, Japan, 2004. 
3. Hydrogen from Coal Program: Research, Development and Demonstration Plan for the Period 2008 through 2016; External Report; US Department of Energy: Dallas, TX, USA, September 2008.

4. Energy Statistics Handbook, Third Quarter; Catalogue No. 57-601-X; Statistics Canada: Winnipeg, MB, Canada, 2008.

5. Bowman, C.W.; Griesbach, R.C. Energy Pathways Task Force Phase I Final Report; Canadian Academy of Engineering: Ottawa, ON, Canada, 2007.

6. Climate Change and Water; Bates, B.C., Kundzewicz, Z.W., Wu, S., Palutikof, J.P., Eds.; Technical Paper; Intergovernmental Panel on Climate Change (IPCC) Secretariat: Geneva, Switzerland, 2008.

7. Charting the Course: A Program Roadmap for Canada's Transition to a Hydrogen Economy; Government of Canada's Hydrogen and Fuel Cell Committee: Ottawa, ON, Canada, August 2005.

8. Overview of the American Recovery and Reinvestment Act of 2009; US Department of Energy: Washington, DC, USA, 2009.

9. Canada's Economic Action Plan; Budget; Government of Canada: Ottawa, ON, Canada, 2009.

10. Evans, A.; Strezov, V.; Evans, T.J. Assessment of sustainability indicators for renewable energy technologies. Renew. Sustain. Energy Rev. 2009, 13, 1082-1088.

11. Afgan, N.H.; Carvalho, M.G. Sustainability assessment of hydrogen energy systems. Int. J. Hydrogen Energ. 2004, 29, 1327-1342.

12. Krajnc, D.; Glavic, P. How to compare companies on relevant dimensions of sustainability. Ecol. Econ. 2005, 55, 551-563.

13. Nessa, B.; Urbel-Piirsalua, E.; Anderbergd, S.; Olsson L. Categorising tools for sustainability assessment. Ecol. Econ. 2007, 60, 498-508.

14. Singh, R.K.; Murty, H.R.; Gupta, S.K.; Dikshit, A.K. An overview of sustainability assessment methodologies. Ecol. Indi. 2009, 9, 189-212.

15. Brown, M.T.; Cohen, M.J.; Sweeney, S. Predicting national sustainability: The convergence of energetic, economic and environmental realities. Ecol. Model. 2009, 220, 3424-3438.

16. Graedel T.E.; Allenby, B.R. Industrial Ecology and Sustainable Engineering; Prentice Hall: New York, NY, USA, 2010.

17. Ayres, R.U.; Turton, H.; Casten, T. Energy efficiency, sustainability and economic growth. Energy 2007, 32, 634-648.

18. Hammond, G.P. Towards sustainability: Energy efficiency, thermodynamic analysis, and the "two cultures". Energ. Policy 2004, 32, 1789-1798.

19. Dincer, I.; Rosen, M.A. Exergy: Energy, Environment and Sustainable Development; Elsevier: Oxford, UK, 2007.

20. Rosen, M.A. Towards energy sustainability: A quest of global proportions. Forum Public Policy: J. Oxford Round Table 2008, June, 1-20.

21. Rosen, M.A. Energy efficiency and sustainable development. Int. J. Global Energy Issues 2002, 17, 23-34.

22. Haas, R.; Nakicenovic, N.; Ajanovic, A.; Faber, T.; Kranzl, L.; Muller, A.; Resch, G. Towards sustainability of energy systems: A primer on how to apply the concept of energy services to identify necessary trends and policies. Energ. Policy 2008, 36, 4012-4021. 
23. Uhrig, R.E.; Schultz, K.R.; Bogart, S.L. Hydrogen economy implementation with synfuels. Encycl. Energy Eng. Technol. 2008, doi:10.1081/E-EET-120044674.

24. Zhou, Z.; Jiang, H.; Qin, L. Life cycle sustainability assessment of fuels. Fuel 2007, 86, 256-263.

25. Zvolinschi, A.; Kjelstrup, S.; Bolland, O.; van der Kooi, H.J. Exergy sustainability indicators as a tool in industrial ecology. J. Ind. Ecol. 2007, 11, 85-98.

26. Hennicke, P.; Fischedick, M. Towards sustainable energy systems: The related role of hydrogen. Energ. Policy 2006, 34, 1260-1270.

27. Dunn, S. Hydrogen futures: Toward a sustainable energy system. Int. J. Hydrogen Energ. 2002, 27, 235-264.

28. Midilli, A.; Dincer, I. Key strategies of hydrogen energy systems for sustainability. Int. J. Hydrogen Energ. 2007, 32, 511-524.

29. Energy Technology Perspectives 2008: Scenarios and Strategies to 2050; International Energy Agency: Beaumont, TX, USA, 2008.

30. Energy Supply and Demand in Canada 2007; Catalogue No. 57-003-X; Statistics Canada: Winnipeg, MB, Canada, 2007.

31. Committee on Alternatives and Strategies for Future Hydrogen Production and Use; Board on Energy and Environmental Systems; Division on Engineering and Physical Sciences; National Research Council and National Academy of Engineering of the National Academies. The Hydrogen Economy: Opportunities, Costs, Barriers, and R\&D Needs; National Academies Press: Washington, DC, USA, August 2004.

32. Hydrogen Systems: The Canadian Opportunity for Greenhouse Gas Reduction and Economic Growth through the Deployment of Hydrogen Technologies and Infrastructures; Canadian Hydrogen Association: Trois Rivieres, QC, Canada, 2005.

33. Muradov, N.Z.; Veziroglu, T.N. "Green" path from fossil-based to hydrogen economy: An overview of carbon-neutral technologies. Int. J. Hydrogen Energ. 2008, 33, 6804-6839.

34. Industrial Size Gasification for Syngas, Substitute Natural Gas and Power Production; Report No. DOE/NETL-401/040607; National Energy Technology Laboratory, US Department of Energy: Washington, DC, USA, April 2007.

35. Alternative Fuels in Canada; Catalogue No. M144-180/2008E-PDF; Office of Energy Efficiency, Natural Resources Canada: Ottawa, ON, Canada, 2008.

36. Canada's Carbon-Dioxide Capture and Storage Roadmap; CANMET Energy Technology Centre, Natural Resources Canada: Ottawa, ON, Canada, 2006.

37. Canada's Fossil Energy Future: The Way Forward on Carbon Capture and Storage; Ecoenergy Carbon Capture and Storage Task Force, Government of Alberta: Edmonton, AB, Canada, 9 January 2008.

38. Energy Policies of IEA Countries: Canada 2004 Review; International Energy Agency: Beaumont, TX, USA, 2004.

39. Hydrogen and Fuel Cells-Canadian Governments: Partners for the Hydrogen Future; Industry Canada: Ottawa, ON, Canada, 2009.

40. Higman, C.; van der Burgt, M. Gasification, 2nd ed.; Elsevier Science: New York, NY, USA, 2008 . 
41. The National Energy Modeling System: An Overview 2003; Energy Information Administration, US Department of Energy: Washington, DC, USA, 2003.

42. Government of Canada; Hydrogen and Fuel Cells Canada; PricewaterhouseCoopers. Canadian Hydrogen and Fuel Cell Sector Profile 2007; Industry Canada: Ottawa, ON, Canada, 2007.

43. Energy Policies of IEA Countries 2006; International Energy Agency: Beaumont, TX, USA, 2006.

44. Human Activity and the Environment-Energy in Canada; Catalogue No. 16-201-XIE; Statistics Canada: Winnipeg, MB, Canada, 2004.

45. World Energy Outlook 2008; International Energy Agency: Washington, DC, USA, 2008.

46. Thumann, A.; Mehta, P.D. Handbook of Energy Engineering, 6th ed.; Fairmont Press: New York, NY, USA, 2008.

47. Mozaffarian, M.; Zwart, R.W.R.; Boerrigter, H.; Deurwaarder, E.P.; Kersten, S.R.A. "Green gas" as SNG (synthetic natural gas): A renewable fuel with conventional quality. In Proceedings of Science in Thermal and Chemical Biomass Conversion Conference, Victoria, BC, Canada, 30 August-2 September 2004; Paper No. ECN-RX-04-085.

48. Shackley, S.; Gough, C. Carbon Capture and Its Storage: An Integrated Assessment, Illustrated edition; Ashgate Publishing: Burlington, VT, USA, 2006.

49. Greenhouse Gas Impacts of Expanded Renewable and Alternative Fuels Use; Report No. EPA420-F-07-035; US Environmental Protection Agency: Anchorage, AK, USA, 2007.

50. Human Activity and the Environment-Solid Waste in Canada; Catalogue No. 16-201-XIE; Statistics Canada: Winnipeg, MB, Canada, 2005.

51. Transport Gasifier IGCC Base Cases; Report No. PED-IGCC-98-006; Process Engineering Division, National Energy Technology Laboratory, US Department of Energy: Washington, DC, USA, June 2000.

52. Cheremisinoff, N.P. Handbook of Chemical Processing Equipment; Butterworth-Heinemann Elsevier: Oxford, UK, 2000.

53. Tchobanoglous, G.; Kreith, F. Handbook of Solid Waste Management, 2nd ed.; McGraw-Hill: Columbus, OH, USA, 2002.

54. Dalcor Consultants; Intuit Strategy. Canadian Hydrogen: Current Status and Future Prospects; Natural Resources Canada: Ottawa, ON, Canada, 2004.

55. Canadian Natural Gas: Review of 2006 and Outlook to 2020; Natural Gas Division, Natural Resources Canada, Ottawa, ON, Canada, December 2007.

56. Canada's Hydrogen and Fuel Cell Industry: Capabilities Guide 2008; Hydrogen \& Fuel Cells Canada (H2FCC): Vancouver, BC, Canada, 2008.

57. Climate Technology Sheet No. 9: Hydrogen Production; CAN-Europe Tech Sheet 09; Climate Action Network Europe: Brussels, Belgium, November 2003; Available online: http://www.climnet.org/ (accessed on 26 May 2010).

58. Index of Consumer Attitudes; Database; Conference Board of Canada: Ottawa, ON, Canada, 2009.

59. Fitzgibbons, K. Future prospects and public policy implications for hydrogen and fuel-cell technologies in Canada. In Making Choices about Hydrogen: Transport Issues for Developing Countries; Mytelka, L.K., Boyle, G., Eds.; United Nations University Press: Tokyo, Japan; International Development Research Centre: Ottawa, ON, Canada, 2008. 
60. Mountouris, A.; Voutsas, E.; Tassios, E. Plasma gasification of sewage sludge: Process development and energy optimization. Energ. Conv. Manage. 2008, 49, 2264-2271.

61. Lewis, F.M. Generation of an Ultra-Superheated Steam Composition and Gasification Therewith. US Patent No. US 7,229,483 B2, 12 June 2007.

62. Weimer, A.W.; Perkins, C.; Mejic, D.; Lichty, P. Rapid Solar Thermal Conversion of Biomass to Syngas. US Patent Application No. US 2008/0086946 A1, 17 April 2008.

63. Stiegel, G.J.; Ramezan, M. Hydrogen from coal gasification: An economical pathway to a sustainable energy future. Int. J. Coal Geol. 2006, 65, 173-190.

64. Recovering Maximum Value from Ottawa's Waste; Plasco Energy Group: Ottawa, ON, Canada, 2008.

65. UK Biomass Strategy 2007; UK Department for Environment, Food and Rural Affairs: London, UK, 2007.

66. Market Opportunities for Biogas Recovery Systems; Report No. 430-8-06-004; US Environmental Protection Agency: Anchorage, AK, USA, 2006.

67. Weersink, A.; Mallon, S. The Financial Feasibility of Anaerobic Digestion for Ontario's Livestock Industries; Department of Food, Agricultural and Resource Economics, University of Guelph: Guelph, ON, Canada, 2007.

68. Electricity Market Module; Report No. DOR/EIA-0554; Energy Information Administration, US Department of Energy: Washington, DC, USA, 2007.

69. Yoshida, Y.; Dowaki, K.; Matsumura, Y.; Matsuhashi, R.; Li, D.; Ishitani, H.; Komiyama, H. Comprehensive comparison of efficiency and $\mathrm{CO}_{2}$ emissions between biomass energy conversion technologies-position of supercritical water gasification in biomass technologies. Biomass Bioenerg. 2003, 25, 257-272.

70. Jin, H.; Ishida, M. A new type of coal gas fueled chemical-looping combustion. Fuel 2004, 83, 2411-2417.

71. Duerr, M.; Gair, S.; Cruden, A. Hydrogen and electrical energy from organic waste treatment. Int. J. Hydrogen Energ. 2007, 32, 705-709.

72. The Elorin Bioenergy Feasibility Study: Anaerobic Digestion for Bioelectricity Production; Goodfellow Agricola Consultant: Dunrobin, ON, Canada, 2007.

73. Zedtwitz, P.V.; Steinfeld, A. The solar thermal gasification of coal: Energy conversion efficiency and $\mathrm{CO}_{2}$ mitigation potential. Energy 2003, 28, 441-456.

74. Cormos, C.C.; Starr, F.; Tzimas, E.; Peteves, S. Innovative concepts for hydrogen production processes based on coal gasification with $\mathrm{CO}_{2}$ capture. Int. J. Hydrogen Energ. 2008, 33, 1286-1294.

(C) 2010 by the authors; licensee MDPI, Basel, Switzerland. This article is an Open Access article distributed under the terms and conditions of the Creative Commons Attribution license (http://creativecommons.org/licenses/by/3.0/). 